\title{
Urinary cGMP concentrations in severe primary pulmonary hypertension
}

Miron Bogdan, Marc Humbert, Jeanne Francoual, Catherine Claise, Pierre Duroux, Gérald Simonneau, Albert Lindenbaum

\begin{abstract}
Background-Prognostic evaluation of patients with primary pulmonary hypertension (PPH) requires right heart catheterisation. The development of accurate non-invasive methods for monitoring these patients remains an important task. Cyclic guanosine monophosphate (cGMP) is an indicator of the action of natriuretic peptides and nitric oxide on target cells. Plasma and urinary cGMP concentrations are raised in patients with congestive heart failure in whom they correlate closely with haemodynamic parameters and disease severity. The aim of the present study was to determine whether the urinary concentration of cGMP could be used as a non-invasive marker of haemodynamic impairment in patients with severe PPH.
\end{abstract}

Methods-Urinary cGMP concentrations were measured in 19 consecutive patients with PPH, seven with acute asthma, and 30 normal healthy controls.

Results-Patients with PPH had higher urinary cGMP concentrations than asthmatic patients or normal healthy controls $(p=0.001)$. Urinary cGMP concentrations were higher in patients with severe haemodynamic impairment-that is, those with a cardiac index (CI) of $\leqslant 2$ / $\mathrm{min} / \mathrm{m}^{2}(\mathrm{p}=0.002)$-and urinary cGMP concentrations were inversely correlated with CI $(r=-0.69, p=0.002)$ and venous oxygen saturation $(r=-0.65, \mathrm{p}=0.003)$. Conclusion-Urinary cGMP concentrations may represent a non-invasive indicator of the haemodynamic status of patients with severe PPH.

(Thorax 1998;53:1059-1062)

Keywords: 3'-5'-cyclic guanosine monophosphate; haemodynamics; pulmonary hypertension

Primary pulmonary hypertension (PPH) is defined by the presence of pulmonary hypertension (mean pulmonary artery pressure $>25 \mathrm{~mm} \mathrm{Hg}$ at rest or $>30 \mathrm{~mm} \mathrm{Hg}$ during exercise), normal pulmonary wedge pressure, and the absence of a secondary cause such as parenchymal lung disease, congenital heart disease, pulmonary vasculitis, collagen vascular disease, and obstruction of pulmonary large vessels including chronic thromboembolic disease. ${ }^{12} \mathrm{PPH}$ is a severe condition, difficult to assess and to control. Treatment is based on vasodilator agents such as calcium channel inhibitors and prostacyclin, anticoagulation, and lung or heart-lung transplantation. ${ }^{3-5}$ Prognostic evaluation of these patients requires invasive procedures, the most reliable data being provided by right heart catheterisation. ${ }^{67}$ The development of accurate non-invasive methods for monitoring these patients remains an important task.

Cyclic guanosine monophosphate (cGMP) an intracellular second messenger of nitric oxide (NO), bradykinin, and natriuretic peptides - acts to regulate the haemodynamic status. ${ }^{8}$ cGMP is an indirect marker of natriuretic peptides or nitric oxide production; it is produced by the activation of the enzyme guanylate cyclase which is present intracellularly in two forms: a cytosolic form activated by NO and a membrane bound form activated by natriuretic peptides including atrial and brain natriuretic peptide (ANP and BNP) ${ }^{8-10}$ Plasma and urinary cGMP concentrations correlate with the plasma concentrations of natriuretic peptides. ${ }^{11}{ }^{12}$ Urinary cGMP is of plasma origin (after glomerular filtration), but is also produced locally as a result of the action of natriuretic peptides on the collecting ducts. ${ }^{13}$ Excreted urinary cGMP levels are therefore dependent on both cGMP plasma levels and renal function. ${ }^{14}$ Since the increase in plasma cGMP appears to be closely associated with the plasma concentration of natriuretic peptides, cGMP is assumed to be an indicator of the action of natriuretic peptides on target cells ${ }^{12}$ leading to natriuresis, diuresis, vasodilation, and anti-renin/angiotensin activity. ${ }^{15}$ Plasma and urinary cGMP concentrations and plasma concentrations of ANP and BNP are increased in patients with congestive heart failure where they are closely correlated with the haemodynamic parameters and disease severity. ${ }^{10} 1116$ Similarly, increased plasma concentrations of natriuretic peptides have been found in patients with $\mathrm{PPH}$ or pulmonary hypertension secondary to chronic obstructive pulmonary disease. ${ }^{17-22}$ In patients with pulmonary hypertension secondary to chronic obstructive pulmonary disease Adnot and colleagues showed that these values correlated with the clinical and haemodynamic profile of the patients, increasing with decompensation and oedema and decreasing with clinical and haemodynamic improvement. ${ }^{19}$

To test the hypothesis that the urinary cGMP concentration could be regarded as a non-invasive marker of haemodynamic impairment in patients with severe PPH, we determined whether there was a correlation between urinary cGMP levels and haemodynamic
26 May 1998

Accepted for publication

9 July 1998 
parameters of PPH severity measured by right heart catheterisation.

\section{Methods}

PATIENTS

Nineteen consecutive non-smoking patients (11 women) of mean (SD) age 43 (4) years with severe PPH were included in the study. $\mathrm{PPH}$ was diagnosed according to the NIH criteria. ${ }^{1}$ All patients were referred to the Service de Pneumologie et Réanimation Respiratoire at the Hôpital Antoine Béclère for diagnostic right heart catheterisation and acute vasodilator challenge. Patients with significant renal disease, infection, malignancy, those who were HIV positive, and all patients receiving active vasodilator treatment were excluded. Personal consent was obtained from all patients for urine collection. We also collected urine samples from seven patients hospitalised for acute asthma (five non-pregnant women and two men) and from 30 normal healthy non-smoking volunteers (20 non-pregnant women and 10 men) of mean (SD) age 45 (7) years.

\section{HAEMODYNAMIC STUDIES}

All patients with PPH underwent diagnostic right heart catheterisation under standard conditions. Swan-Ganz catheters were used to measure resting right atrial pressure (RAP), systolic and diastolic pulmonary artery pressure (PAP), and pulmonary wedge pressure. The cardiac output (in triplicate) was determined using the flow directed thermodilution technique and the cardiac index (CI) was calculated. Blood samples from the pulmonary artery were collected for determining mixed venous oxygen saturation $\left(\mathrm{SvO}_{2}\right)$. Mean pulmonary artery pressure (mPAP) and total pulmonary vascular resistance (TPVR) were calculated. Right heart catheterisation was performed $24-48$ hours after urine sample collection.

\section{SAMPLE COLLECTION}

Single spot urine samples, both in patients and in controls, were collected between 08.00 and 10.00 hours in sterile vials and placed immediately on ice, put into aliquots, and stored at $-20^{\circ} \mathrm{C}$. Cyclic GMP determination was performed using an immunoreactive method and measured by radioimmunoassay (cGMP assay RPA 525; Amersham, Bucks, UK). ${ }^{23}$ Urine samples were diluted 10 and 100 fold in buffer assay. Urinary creatinine concentrations were determined enzymatically in parallel and data were given as cGMP excretion rates (nmol cGMP/mmol creatinine) to avoid interference with variable renal excretory function. ${ }^{24}$ The intra-assay and inter-assay variations were each less than $10 \%$. Plasma creatinine concentrations were within the normal range in all patients.

ANALYSIS OF DATA

Data were analysed with a Macintosh computer (Apple Company, New York, USA) using the Statview 4.5 software (Abacus Concepts Inc, Berkeley, California, USA). Normally distributed data were analysed for between group

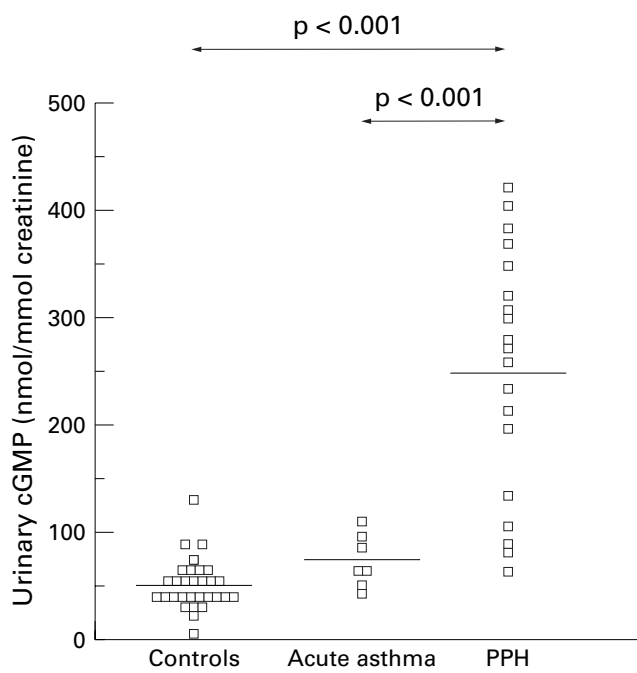

Figure 1 Urinary cGMP excretion rates in patients with severe primary pulmonary hypertension (PPH), acute asthma, and in normal healthy controls.

comparison using the unpaired Student's $t$ test and non-normally distributed data were analysed with the two tailed Mann-Whitney U test. Mean (SE) values are presented in the text and the accompanying figures. Correlation coefficients were obtained by standard linear regression techniques. $\mathrm{p}$ values of $<0.05$ were considered significant.

\section{Results}

In patients with $\mathrm{PPH}$ the RAP, mPAP, CI, TPVR, and $\mathrm{SvO}_{2}$ were 13 (1) $\mathrm{mm} \mathrm{Hg}, 64$ (3) $\mathrm{mm} \mathrm{Hg}, \quad 2.23 \quad(0.14) \mathrm{l} / \mathrm{min} / \mathrm{m}^{2}, \quad 31.1$ (2.7) $\mathrm{mm} \mathrm{Hg} / 1 / \mathrm{min} / \mathrm{m}^{2}$, and 55 (2)\%, respectively. All patients had severe dyspnoea (functional class III or IV) and impaired exercise capacity was demonstrated using the unencouraged six minute walk test (344 (28) metres).

Urinary cGMP excretion rates were significantly increased in patients with PPH (251 (26) $\mathrm{nmol} / \mathrm{mmol}$ creatinine) compared with normal healthy controls (51 (4) nmol/mmol creatinine, $p=0.001$ ) and patients with acute asthma (71 (8) $\mathrm{nmol} / \mathrm{mmol}$ creatinine, $\mathrm{p}=$

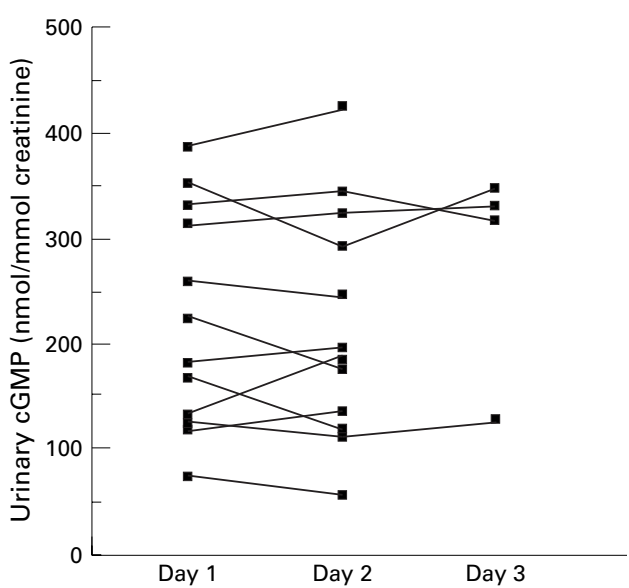

Figure 2 Day to day cGMP excretion rates variability in 12 patients with primary pulmonary hypertension from whom urinary samples were collected on two or three consecutive days. 


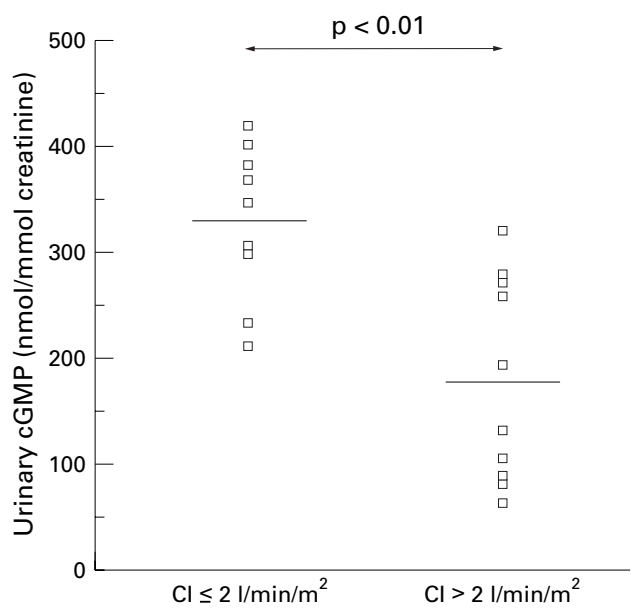

Figure 3 Urinary cGMP excretion rates in patients with cardiac index $(C I)$ of $\leqslant 2 \mathrm{l} / \mathrm{min} / \mathrm{m}^{2}$ and $>2 \mathrm{l} / \mathrm{min} / \mathrm{m}^{2}$.

0.001 ; fig 1). There was no difference between male and female patients with PPH (262 (39) and $236(36) \mathrm{nmol} / \mathrm{mmol}$ creatinine, respectively, $\mathrm{p}>0.5)$. In order to determine whether urinary cGMP concentrations fluctuate in a single individual, urinary samples were collected from 12 patients with $\mathrm{PPH}$ on two or three separate occasions; day to day cGMP urinary excretion variability was limited with a mean variation of $15 \%$ (fig 2 ).

Poor prognosis in $\mathrm{PPH}$ is associated with a low CI $\left(\leqslant 21 / \mathrm{min} / \mathrm{m}^{2}\right)$ and low $\mathrm{SvO}_{2}(\leqslant 60 \%){ }^{67}$ We therefore separated our patient population into two groups according to these validated haemodynamic markers of severity. Significantly higher cGMP urinary concentrations (330 (26) $\mathrm{nmol} / \mathrm{mmol}$ creatinine) were found in patients with a low CI $(n=9)$ than in those with a CI of $>21 / \mathrm{min} / \mathrm{m}^{2}$ (180 (31) $\mathrm{nmol} / \mathrm{mmol}$ creatinine, $\mathrm{n}=10, \mathrm{p}<0.01$; fig 3 ). In patients with $\mathrm{PPH}$ urinary cGMP concentrations were inversely correlated with CI $(r=-0.65, \mathrm{p}=$ 0.003; fig 4). Statistical analysis failed to show a significant increase in cGMP urinary concentrations in patients with $\mathrm{SvO}_{2}$ of $\leqslant 60 \%$ (278 (28) $\mathrm{nmol} / \mathrm{mmol}$ creatinine, $\mathrm{n}=14$ ) compared with those with $\mathrm{SvO}_{2}$ of $>60 \%(146$ (88) nmol/ mmol creatinine, $\mathrm{n}=5 ; \mathrm{p}=0.12)$. However, there was an inverse correlation between $\mathrm{SvO}_{2}$ and urinary cGMP concentration in patients with PPH $(r=-0.60, \mathrm{p}=0.01)$. There was no

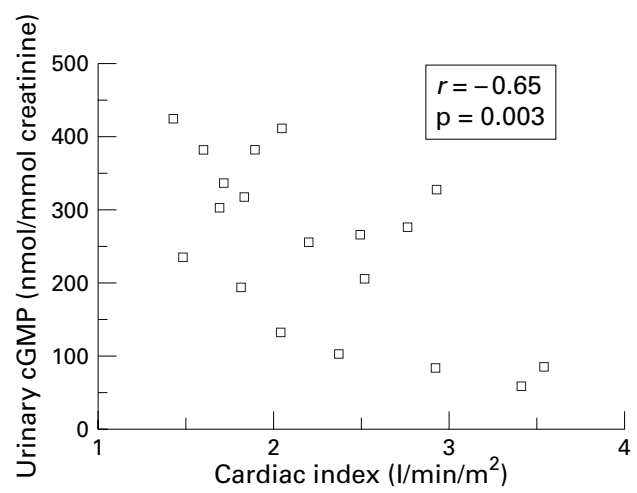

Figure 4 Correlation between urinary cGMP excretion rates and cardiac index in patients with severe primary pulmonary hypertension. significant correlation between cGMP urinary concentrations and exercise capacity, mPAP, or RAP.

\section{Discussion}

$\mathrm{PPH}$ is a severe condition and its monitoring usually requires repeated invasive procedures such as right heart catheterisation. ${ }^{67}$ The development of a non-invasive method for assessing the haemodynamic status of these patients is of major clinical importance. In this study we have shown that patients with severe PPH have increased urinary cGMP concentrations compared with patients with respiratory diseases without pulmonary hypertension (such as acute asthma) or normal healthy controls. Moreover, urinary cGMP concentrations were higher in patients with severe haemodynamic impairment (CI $\leqslant 21 / \mathrm{min} / \mathrm{m}^{2}$ ) and urinary cGMP concentrations were inversely correlated with $\mathrm{CI}$ and $\mathrm{SvO}_{2}$. The urinary cGMP concentration could therefore be regarded as a non-invasive indicator of disease severity in PPH.

Our findings are in agreement with previous studies showing raised urinary cGMP concentrations in patients with cardiac congestive failure of various aetiologies (ischaemic heart disease, valvular heart disease, and cardiomyopathy). ${ }^{11}$ Vorderwinkler and colleagues showed that increased plasma cGMP concentrations were sensitive markers of chronic heart failure. ${ }^{14}$ Similarly, Hirata and coworkers found increased plasma ANP and cGMP concentrations in a large series of patients with chronic heart failure of left ventricular origin and suggested that plasma levels of cGMP reflect the circulating concentrations of natriuretic peptides. ${ }^{16}$ However, plasma levels of cGMP may only reflect a momentary situation in a localised area of the circulation and may have important diurnal variations, whereas urinary levels reflect the cumulative effect of natriuretic peptides over a longer period of time. ${ }^{24}$

Increased plasma ANP concentrations can be detected in patients with pulmonary hypertension complicating severe chronic obstructive pulmonary disease where its levels correlate directly with the degree of haemoconcentration, respiratory acidosis, and pulmonary hypertension. ${ }^{17-19}$ Similarly, pulmonary hypertension secondary to severe interstitial disease is associated with increased plasma ANP levels. ${ }^{20}$ From a physiopathological point of view, patients with PPH represent a model of pure right ventricular failure. Raised plasma ANP levels have been detected in patients with PPH, similar to those found in patients with cardiac congestive failure of primarily left ventricular origin. ${ }^{2122}$

To our knowledge this study is the first to report the measurement of urinary cGMP concentrations in patients with PPH. Importantly, we excluded patients treated with drugs such as nitrates and other vasodilators which may increase cGMP urinary levels.

Natriuretic peptides represent the response of cardiac and vascular myocytes to enhanced wall stress and stretching. ${ }^{25} 26 \mathrm{ANP}$ and BNP production is one of the consequences of the 
myocardial and vascular remodelling which characterises pulmonary hypertension and right ventricular hypertrophy. Urinary cGMP is of plasma origin as a result of renal clearing ${ }^{27}$ and of renal origin as a result of local production by the distal nephron (mostly by the medullary collecting tubules) under the direct action of natriuretic peptides. ${ }^{13}$ As renal failure can modify cGMP urinary levels, we selected patients with normal renal function. Moreover, it is important to note that measurements of cGMP urinary excretion rates (nmol cGMP/ mmol creatinine) are believed to be independent of renal excretory function and could therefore be used in patients with impaired renal function. ${ }^{24}$

In conclusion, we have shown that urinary cGMP determination represents a noninvasive indicator of the haemodynamic status of patients with PPH. Although this marker correlates with validated indicators of disease severity, further studies are needed to evaluate the prognostic value of urinary cGMP concentration in terms of survival and its kinetics during chronic vasodilator therapy.

This work was supported by a grant from Université Paris-Sud. The authors thank Ms Chantal Demaison and the staff of the Service de Pneumologie et Réanimation Respiratoire, Hôpital Antoine Béclère for their technical assistance.

1 Rich S, Dantzer DR, Ayres SM, et al. Primary pulmonary hypertension: a national prospective study. Ann Intern Med 1987; 107:216-23.

2 Rubin LJ. Primary pulmonary hypertension. Chest 1993; 104:236-50.

3 Reitz BA, Wallwork JL, Hunt SA, et al. Heart-lung transplantation: successful therapy for patients with pulmonary vascular disease. N Engl f Med 1982;306:557-64.

4 Rich S, Kaufman E, Levy PS. The effect of high doses of calcium-channel blockers on survival in primary pulmonary hypertension. N Engl f Med 1992;327:76-81.

5 Barst RJ, Rubin LJ, Long WA, et al. A comparison of continuous intravenous epoprostenol (prostacyclin) with continuous intravenous epoprostenol (prostacyclin) with conventional therapy for primary pur

6 D'Alonzo G, Barst RJ, Ayres SM, et al.Survival in patients with primary pulmonary hypertension. Ann Intern Med with primary pulm

7 Brenot F. Primary pulmonary hypertension: case series from France. Chest 1994;105(Suppl):33-6.

8 Shepherd JT, Lüscher TF, Mancia G. Circulatory regulation: basic considerations. In: Willerson JT, Cohn JN eds. Cardiovascular medicine. Churchill Livingstone, 1995 1053.
9 McDonald LJ, Murad F. Nitric oxide and cyclic GMP signaling. Proc Soc Exp Biol Med 1996;211:1-6.

10 Cowie MR, Struthers AD, Wood DA, et al. Value of natriuretic peptides in assessment of patients with possible new heart failure in primary care. Lancet 1997;350:1349-53.

11 Jakob G, Mair J, Vorderwinkler KP, et al. Clinical significance of urinary cyclic guanosine monophosphate in diagnosis of heart failure. Clin Chem 1994;40:96-100.

12 Abraham WT, Hensen J, Kim JK, et al. Atrial natriuretic peptide and urinary cyclic guanosine monophosphate in patients with chronic heart failure. F Am Soc Nephrol 1992; 2:1697-703.

13 Kim JK, Summer SN, Dürr J, et al. Enzymatic and binding effects of atrial natriuretic factor in glomeruli and nephrons. Kidney Int 1989;35:799-805.

14 Vorderwinkler KP, Artner-Dvorzak E, Jakob G, et al. Release of cyclic guanosine monophosphate evaluated as a diagnostic tool in cardiac diseases. Clin Chem 1991;37:18690.

15 Saito Y, Nakao K, Nishimura K, et al. Clinical application of atrial natriuretic polypeptide in patients with congestive heart failure. Circulation 1987;76:115-25.

16 Hirata $Y$, Ishii $M$, Matsuoka $H$, et al. Plasma concentrations of alpha-human atrial natriuretic polypeptide and cyclic GMP in patients with heart diseases. Am Heart f 1987;113: 1463-9.

17 Adnot S, Chabrier PE, Andrivet P, et al. Atrial natriuretic peptide concentrations and pulmonary hemodynamics in patients with pulmonary arterial hypertension. Am Rev Respir Dis 1987;136:951-6.

18 Adnot S, Andrivet P, Chabrier PE, et al. Atrial natriuretic factor in chronic obstructive lung disease with pulmonary hypertension. I Clin Invest 1989;83:986-93.

19 Skwarski K, Lee M, Turnbull L, et al.. Atrial natriuretic peptide in stable and decompensated chronic obstructive peptide in stable and decompensated chronary disease. Thorax 1993;48:730-5.

20 Burghuber OC, Hartter E, Punzengruber C, et al. Human atrial natriuretic peptide secretion in precapillary pulmonary hypertension. Chest 1988;92:31-7.

21 Morice AH, Pepke-Zaba J, Brown MJ, et al. Atrial natriuretic peptide in primary pulmonary hypertension. Eur Respir f 1990;3:910-3.

22 Nootens M, Kaumann E, Recyor T, et al. Neurohormonal activation in patients with right ventricular failure from pulmonary hypertension: relation to hemodynamic variables and endothelin levels. $\mathcal{f}$ Am Coll Cardiol 1995;26: 1581-5.

23 Francoual J, Taieb J, Berkane N, et al. Urinary cGMP levels during pregnancy with and without uterine contractions. Eur F Obstet Gynecol Reprod Biol 1995;63:17-9.

24 Böger RH, Bode-Böger SM. Is measurement of cyclic guanosine monophosphate in plasma and urine suitable for assessing in vivo nitric oxide production. Circulation 1998; 97:1209-10.

25 Edwards BS, Zimmerman RS, Schwab TR, et al. Atrial stretch, not pressure, is the principal determinant controlling the acute release of natrial natriuretic peptide. Circ Res 1988;62:191-5.

26 Yasue $\mathrm{H}$, Yoshimura $\mathrm{M}$, Sumida $\mathrm{H}$, et al. Localization and mechanism of secretion of B-type natriuretic peptide in comparison with those of A-type natriuretic peptide in normal subjects and patients with heart failure. Circulation 1994;90:195-203.

27 Broadus AE, Kaminski NI, Hardman JG, et al. Kinetic parameters and renal clearences of plasma adenosine 3',5'monophosphate and guanosine $3^{\prime}, 5^{\prime}$-monophosphate in man. $\mathcal{F}$ Clin Invest 1970;49:2222-36. 